\title{
Analysis of Air Quality in A Laboratory Equipped with Split Air Conditioning System
}

\author{
Mayuresh Pingale \\ PG student, Mechanical Engineering Department, \\ Sardar Patel college of Engg, \\ Mumbai, India
}

\author{
Kunal Bhavsar \\ Faculty ,Mechanical Engineering Department, \\ Sardar Patel college of Engg, \\ Mumbai, India
}

\begin{abstract}
Computer laboratories are the place for teaching and learning where thermal conditions and indoor air quality is essential for the performance of students and teachers. Computational fluid dynamics is a widely used technique which is used to simulate indoor air conditions. This study includes experimental as well as numerical work using computational fluid dynamics program of a computer laboratory /with high wall mount split air conditioning system. Experimental results are compared with the numerical one to evaluate the CFD program. $\mathrm{CO}_{2}$ concentration field measurements were taken which is standard to check indoor air quality of the computer laboratory. Cooling load requirement of the laboratory is also evaluated in this study. Twelve points were considered in laboratory to take reading for temperature, humidity and $\mathrm{CO}_{2}$ concentration. $\mathrm{CO}_{2}$ concentration exceeded the permissible as well as hazardous limit set by ASHRAE standard 62.1,2013. Good agreement is achieved between the computed and measured temperature results. The experimental and numerical results showed that the model is capable of giving close results with experimental one and due to this modifying the model can give a better air temperature distribution. The simulation also showed the existence of cold spots and stagnant are in the laboratory.
\end{abstract}

Keywords - Indoor air quality; Computational fluid dynamics; laboratory; split air conditioning system; $\mathrm{CO}_{2}$ concentration.

\section{INTRODUCTION}

Air conditioning, as the name suggests conditioning of air i.e. treating air or altering its properties and bringing it to the required predefine composition for the comfort of the occupant is the primary purpose. In air conditioning basically the heat content of air i.e. sensible and latent heat is removed by means of mechanism that use the three mode of heat transfer i.e. conduction, convection and radiation. In convection based air conditioning, air is forced to pass over a cooled surface with the help of fans and blowers. While the air is moving over the surface, it gets cooled and is then send to the occupant space. In split air conditioning systems air is delivered at the ceiling level at a predefined lower temperature. Air is supplied at high velocity to provide efficient mixing of supply air with room air to provide uniform temperature throughout the space.

It is found that human beings spend most of their time in enclosed spaces, such as houses, office buildings, and schools and such spaces have restricted air circulation. Ventilation here plays a important role for comfort and health of occupants in the room but in split air conditioning system return air is again recirculated in the system. So in absence of ventilation, indoor air quality may be worse than outdoor air quality. Measuring the indoor $\mathrm{CO}_{2}$ concentration is often used as an alternative to determine the indoor air quality. $\mathrm{CO}_{2}$ is a natural air component and in a given air sample it is commonly expressed in parts per million (ppm).If indoor $\mathrm{CO}_{2}$ levels are more than $1000 \mathrm{ppm}$, ventilation is probably inadequate, and occupants may commonly complain about headaches, nose and throat ailments, tiredness, lack of concentration, and fatigue. Classrooms function as the basic space where teaching and learning are the main priority therefore, indoor air quality issues in classrooms are seen as risks.

Since fresh air supply and distribution plays such an important role in determining the indoor environment, accurate prediction of the air flow in occupied spaces is crucial for designing an effective air distribution system. Computational fluid dynamics (CFD) has been used for prediction of room air movement for a long time now. In recent years much effort has been made to enhance CFD as a reliable tool for the evaluation of indoor thermal comfort and air quality[9].Compared with experimental studies of indoor environment CFD is less expensive and can obtain results much faster, due to the development in computing power and capacity as well as turbulence modeling. CFD can be applied to test flow and heat transfer conditions where experimental testing could prove very difficult[10].

M Raman 2016[11] simulated a school auditorium using the computational fluid dynamics technique to evaluate airflow velocity, pressure, and temperature. Two modeling scenarios were investigated, one being the existing system and other being the system designed using displacement ventilation .CFD simulation for both the existing and proposed systems demonstrate stagnation of air and higher temperatures in the back stalls and circle area.

M Hussin et. al. 2017[13] evaluated the indoor $\mathrm{CO}_{2}$ levels in ten mechanically ventilated laboratories and to identify necessary improvements. High $\mathrm{CO}_{2}$ concentration in laboratories 1 and 10 indicates a minimum laboratory ventilation rate as specified in the codes. $\mathrm{CO} 2$ levels should be reduced to produce laboratory environments that are conducive to learning. The other laboratories had $\mathrm{CO} 2$ concentrations lower than $1000 \mathrm{ppm}$. Merve Kuru et. al 2018[14] studied thermal comfort parameters and $\mathrm{CO}_{2}$ concentrations in a university classroom were gathered via field measurements and occupants' sensation and perceptions are collected via subjective surveys. The PMV indices were calculated to assess the thermal comfort conditions of the classroom. They found that thermal sensation, relative humidity and air velocity perception of occupants have a statistically significant effect on $\mathrm{CO}_{2}$ perceptions of 
occupants. The majority of $\mathrm{CO}_{2}$ concentration measurements exceeded the permissible concentration value of $1000 \mathrm{ppm}$ stated by ASHRAE.

Qinghe Yao et. al. 2018[15] used three computational techniques, namely ,the standard $\mathrm{K}-\varepsilon, \mathrm{RNG} \mathrm{K}-\mathcal{E}$, and the $\mathrm{K}-\omega$ model , to numerically simulate and determine the air distribution in an air-conditioned room. The simulation results for all three methods are verified via a comparison with an experiment involving a room that contains a computer server which generates up to $6 \mathrm{~kW}$ of heat. In doing so and by additionally performing an error analysis, it is determined that the $\mathrm{K}-\omega$ model produces the most accurate results.

Limited studies focus air distribution of split air conditioning system and also about indoor air quality for the computer laboratories where occupancy load is large. For this study, a commercially available CFD software tool ANSYS is used with solver engine as Fluent. Studying $\mathrm{CO}_{2}$ concentration along with other thermal indices is very important. $\mathrm{CO}_{2}$ concentration, temperature and humidity measurements are carried out in computer laboratory of Sardar Patel College of engineering at Andheri during practical session. Measurements are conducted in air conditioned laboratories with closed door and windows for $120 \mathrm{~min}$. The lab under consideration has dimension of $11.43 \mathrm{~m} \times 7.63 \mathrm{~m} \times 2.85 \mathrm{~m}$ and has high wall mount three split air conditioning each of 2 Ton capacity. There are 52 people sitting in laboratory each with 450 Btu hr-1 heat load. Also there are 52 C.P.U and LCD each having heat load of $65 \mathrm{~W}$ and 55Wrespectively. Along with above there are 18 double baton tubes each of $20 \mathrm{~W}$.

\section{METHODOLOGY}

\section{A. Heat load calculation}

Heat load calculation is done first to evaluate the required heat load for laboratory. Heat load calculations were done based on following considerations:

- Location : Mumbai

- $\quad$ Building Area: 939 sq. ft.

- DBT : $34.1^{\circ} \mathrm{C}$

- Latitude: $19.12^{\circ} \mathrm{N}$ Longitude $: 72.85^{\circ} \mathrm{E}$

- Mean Daily temp.: $11.8^{\circ} \mathrm{C}$

- U-Overall values of the materials: from ASHRAE standard data book.

\section{a. Room Sensible Heat}

$\mathrm{A} 1=$ Solar gain through glass $=595 \mathrm{Btu} / \mathrm{hr}$

A2 $=$ Heat gain through walls and roofs $=15168$

$\mathrm{Btu} / \mathrm{hr}$

A3 = sensible heat gain from human $=13000$ Btu /hr

A4 = Appliance load $=21216 \mathrm{Btu} / \mathrm{hr}$

A5 $=$ Lightning load $=4468 \mathrm{Btu} / \mathrm{hr}$

Total Room sensible heat

$\mathrm{A}=\mathrm{A} 1+\mathrm{A} 2+\mathrm{A} 3+\mathrm{A} 4+\mathrm{A} 5=54446 \mathrm{Btu} / \mathrm{hr}$ b. Room Latent Heat

$\mathrm{Q}=$ Latent heat gain from human

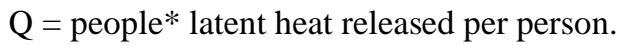

Total Room Latent heat $=\mathrm{Q}=10400 \mathrm{Btu} / \mathrm{hr}$

c. Grand Total Heat

Grand Total Heat $=($ Total Room Sensible heat + Total Room Latent Heat)

Factor of safety $=3 \%$

Grand Total Heat $=(\mathrm{A}+\mathrm{Q}) \times 1.3=67863 \mathrm{Btu} / \mathrm{hr}$

B. Measuring $\mathrm{CO}_{2}$ Concentration using $\mathrm{CO}_{2}$ probe at specified locations in laboratory

C. Measuring temperature and velocity at specified locations in laboratory

D. Modeling the laboratory using SolidWorks software and simulating using ANSYS FLUENT to validate experimental one.

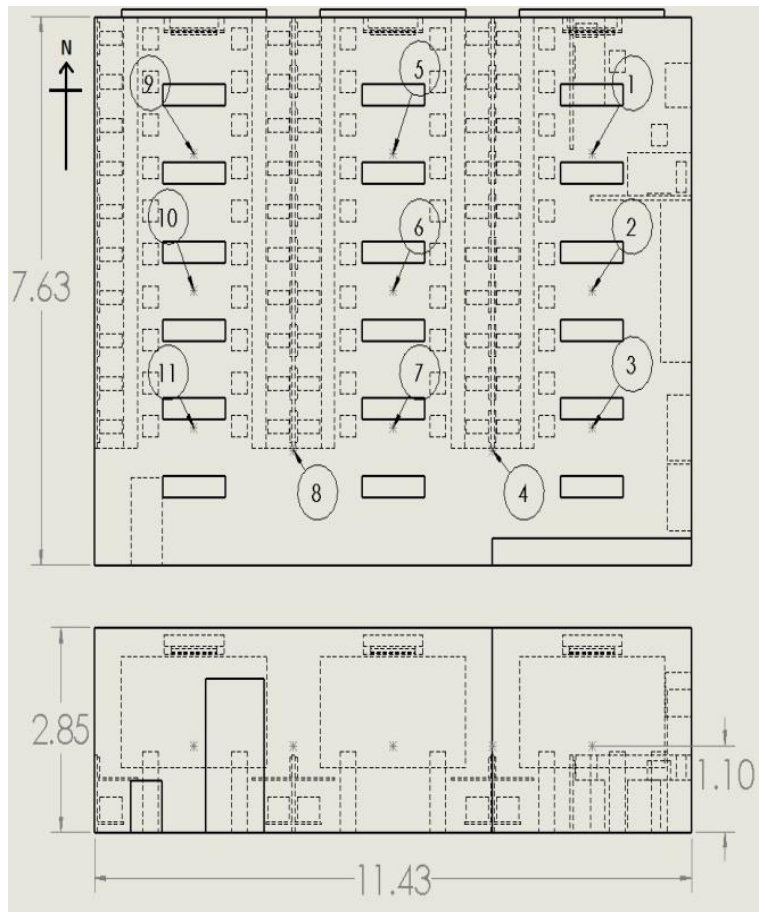

Fig 1. Two-dimensional View of laboratory.

\section{EXPERIMENTATION}

Experimentation is done by taking readings at specified twelve points in laboratory. Points are taken at distance of 1.1 $\mathrm{m}$ from the ground which is breathing zone .Points are located in such a way that it covers approximately the entire air distribution in the laboratory. Fig. 1 is 2D Plan view and Elevation view of laboratory .It also shows different points at which readings were taken for temperature, humidity and $\mathrm{CO}_{2}$. The details of the instrumentation used are given in Table 1. Readings were taken for temperature, humidity and $\mathrm{CO}_{2}$ concentration at intervals of 20 minutes for a total of 120 minutes. 
Instruments used for measurements:

TABLE 1. Measuring Instruments

\begin{tabular}{|c|c|c|}
\hline Instrument & Range & Accuracy \\
\hline Temperature probe & 0 to $50^{\circ} \mathrm{C}$ & $\pm 0.8^{\circ} \mathrm{C}$ \\
\hline Humidity probe & 5 to $95 \%$, & $\pm 3 \%$ of reading \\
\hline $\mathrm{CO}_{2}$ probe & 0 to $4000 \mathrm{ppm}$ & $\pm 5 \%$ of reading \\
\hline
\end{tabular}

Experimental observations:

Data obtained from the experiment is plotted for $\mathrm{CO}_{2}$ concentration, temperature and humidity against time as given in Fig. 2, Fig. 3 and Fig. 4 respectively.

From the Fig. 2 it can see that at the start itself $\mathrm{CO}_{2}$ concentration is $1000 \mathrm{ppm}$.According to ASHRAE standard 62.1 1000ppm is the permissible limit set and it can be seen that at start itself it is exceeding limit. It is due to the fact that room is closed as no ventilation is provided in it .From the Fig. 2 it can be seen that down the line it will eventually cross 5000 ppm mark which is hazardous limit set by ASHRAE. Such situation can cause headaches, dizziness, restlessness, breathing difficulty, increased heart rate, asphyxia, and convulsions.

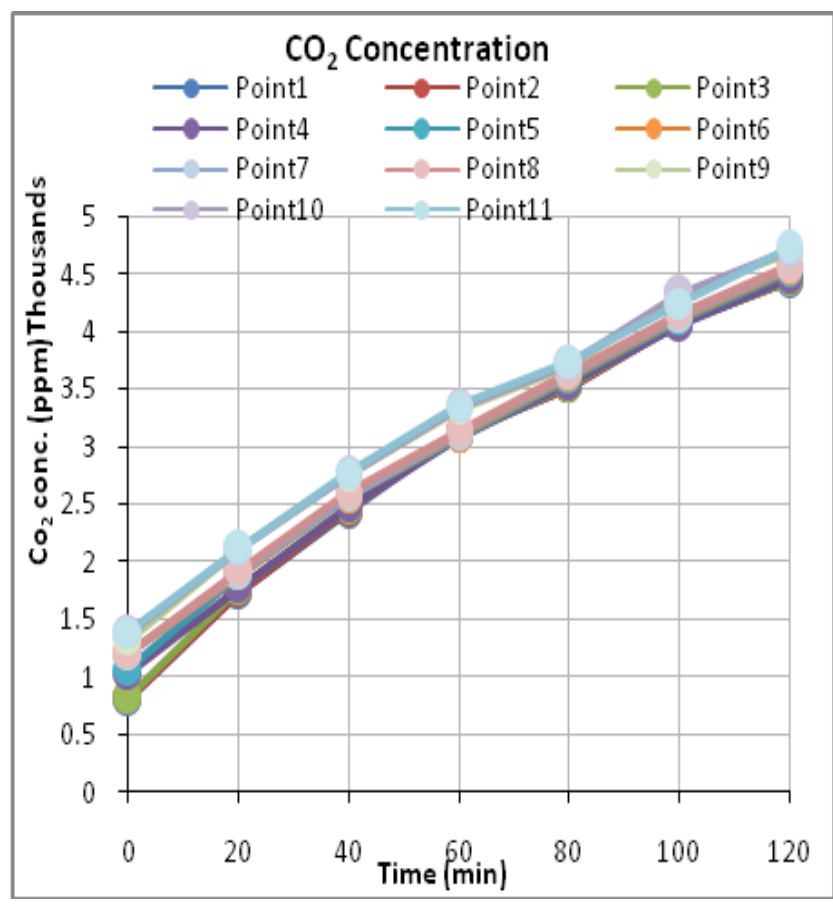

Fig 2. $\mathrm{CO}_{2}$ concentration vs time

From the Fig. 3 it can see that there is steep fall in temperature of room at the start and at the end of time period the line is almost becoming horizontal. The change in temperature for the lab is approximately $4.5^{\circ} \mathrm{C}$.

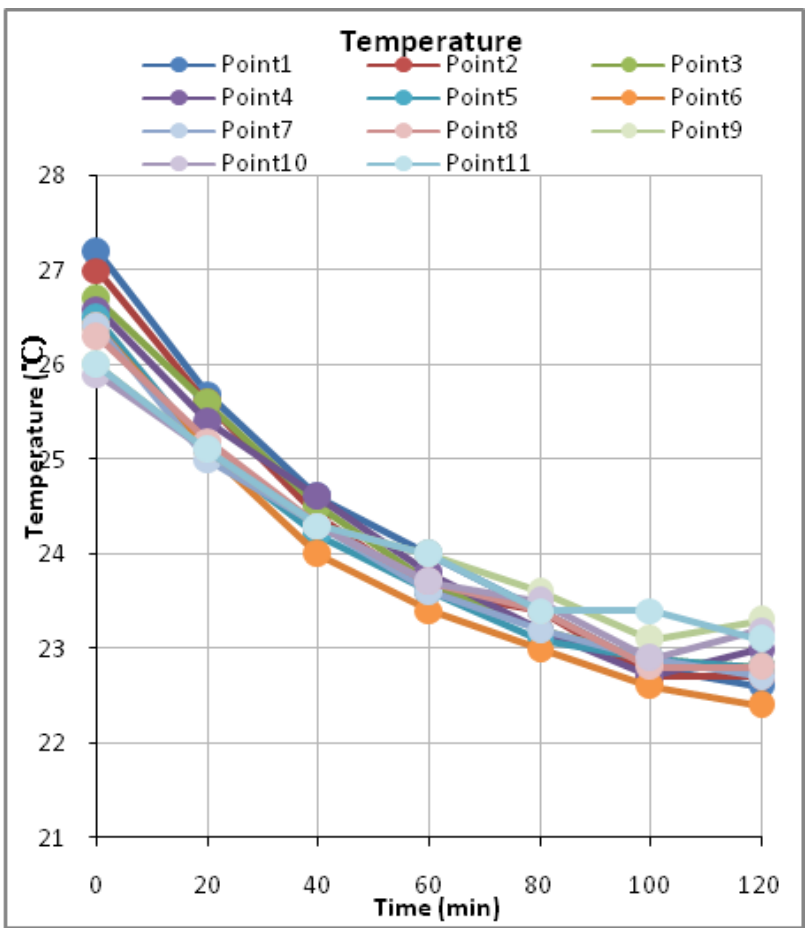

Fig 3. Temperature vs time

It can see from Fig. 4 that at the start humidity was around $54 \%$ to $58 \%$ and there is large fall in humidity of air for first $40 \mathrm{~min}$ after which it almost become stable. This is due to the fact that inlet air coming from air conditioner is dry. So such low level of humidity can cause discomfort for humans.

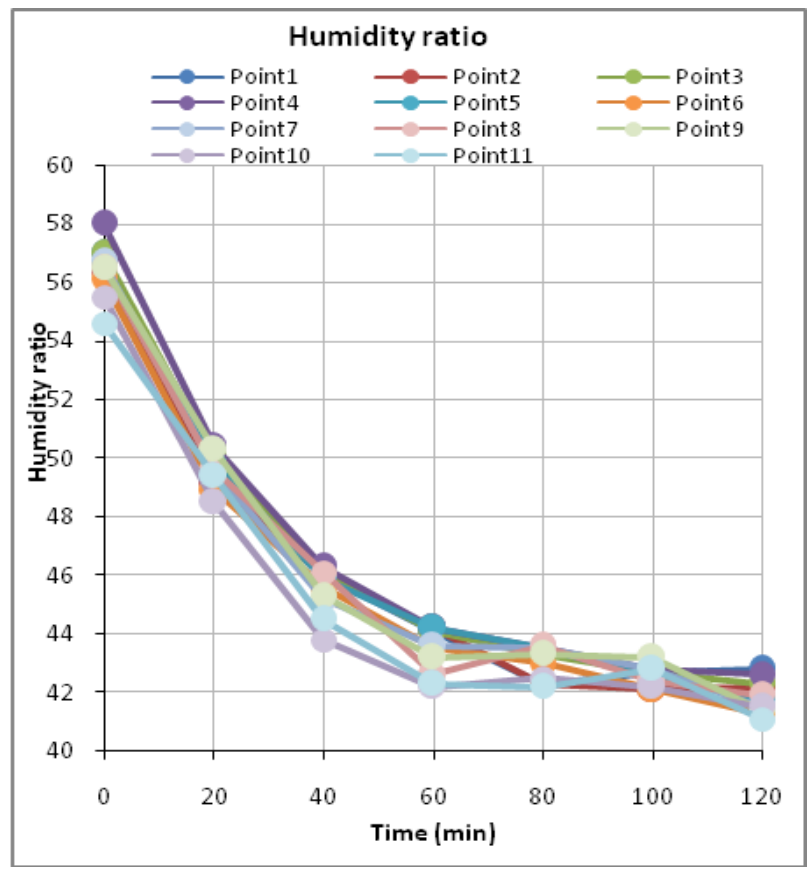

Fig 4. Humidity ratio vs time

\section{ANALYTICAL MODELLING}

To avoid the complexity in meshing instead of human mannequin cuboids were considered of dimension $30 \times 30 \times 110 \mathrm{~cm}$. Dimension of $1 \mathrm{~cd}$ is $48 \times 28 \times 4 \mathrm{~cm}$. Also size of C.P.U is $19 \times 35 \times 41 \mathrm{~cm}$.Fig. 5 shows $3 \mathrm{D}$ model of laboratory made in $\mathrm{CAD}$ software. Indoor unit of the high 
wall mount split air conditioning system can be seen on the north wall. Three large windows of $154 \times 281 \mathrm{~cm}$ on the north wall which is made of glass is framed in the model. For the model tetrahedral mesh is used with average quality of elements 0.82.There are around 262232 elements and 381579 nodes in the mesh .Maximum aspect ratio is 1.166 and minimum orthogonality is 0.0725 .

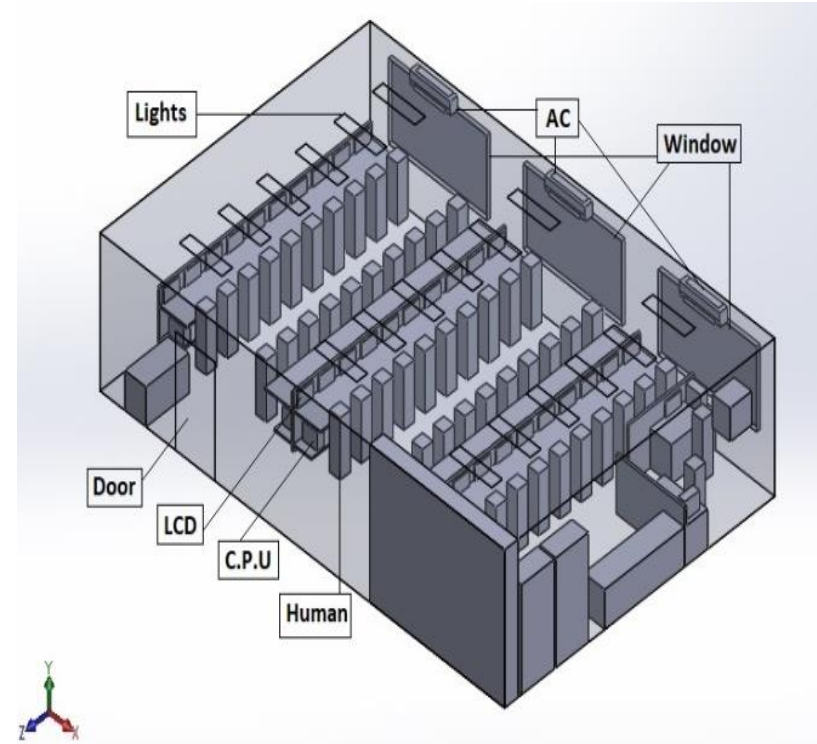

Fig 5. 3D CAD model of laboratory

\section{MATHEMATICAL MODEL AND BOUNDARY CONDITIONS}

Three basic equations of conservation of mass, momentum and energy are used. Mass, momentum, and energy conservation respectively result in the continuity, NavierStokes, and energy equations. Turbulence is present in this scenario so $\mathrm{K}-\omega$ model is used as given in literature. The standard $\mathrm{K}-\omega$ model is based on transport equations for the turbulent kinetic energy and specific rate of dissipation. Standard K- $\omega$ model gives the least error for such indoor air simulations.

The flow is assumed to be three dimensional, unsteady, and turbulent. Convective heat transfer at the walls and windows is calculated using data of heat load calculation and outside air temperature as reference. Air tight model is assumed with no infiltration or ex-filtration present in model. Convergence criteria are set to $1 \times 10^{-3}$ for continuity and momentum equations and for energy it is set to $1 \times 10^{-5}$.

Properties of material is given in table 2

TABLE 2. Material properties

\begin{tabular}{|c|c|}
\hline Property & Value \\
\hline Density & Ideal gas \\
\hline Specific heat & $1006.43 \mathrm{j} / \mathrm{kg} . \mathrm{k}$ \\
\hline Thermal conductivity & $0.0242 \mathrm{w} / \mathrm{m} . \mathrm{k}$ \\
\hline Viscosity & $1.7894 \mathrm{e}-05 \mathrm{~kg} / \mathrm{m} . \mathrm{s}$ \\
\hline Molecular weight & $28.966 \mathrm{~kg} / \mathrm{kgmol}$ \\
\hline
\end{tabular}

Boundary conditions were calculated using data from heat load calculation and ASHRAE handbook are presented in table 3. All the walls were considered as no slip and stationary wall. The heat flux through each wall in $\mathrm{W} / \mathrm{m}^{2}$ is given in table 3 .
TABLE 3. Boundary condition

\begin{tabular}{|c|c|c|}
\hline Name & Type & Condition \\
\hline All three Inlet & $\begin{array}{c}\text { Mass flow } \\
\text { inlet }\end{array}$ & $\begin{array}{c}\dot{\mathrm{m}}=0.24 \mathrm{~kg} / \mathrm{s} \mathrm{\&} \\
\mathrm{T}=7.5^{\circ} \mathrm{C}\end{array}$ \\
\hline All three outlet & $\begin{array}{c}\text { Pressure } \\
\text { outlet }\end{array}$ & $P_{\text {guage }}=0 \mathrm{~Pa}$. \\
\hline North Wall & Wall & $\mathrm{Q}_{\text {flux }}=13.28 \mathrm{w} / \mathrm{m}^{2}$ \\
\hline South Wall & Wall & $\mathrm{Q}_{\text {flux }}=7.04 \mathrm{w} / \mathrm{m}^{2}$ \\
\hline East Wall & Wall & $\mathrm{Q}_{\text {flux }}=3.52 \mathrm{w} / \mathrm{m}^{2}$ \\
\hline West Wall & Wall & $\mathrm{Q}_{\text {flux }}=12.24 \mathrm{w} / \mathrm{m}^{2}$ \\
\hline glass & Wall & $\mathrm{Q}_{\text {flux }}=22.712 \mathrm{w} / \mathrm{m}^{2}$ \\
\hline Ceiling & Wall & $\mathrm{Q}_{\text {flux }}=4.8 \mathrm{w} / \mathrm{m}^{2}$ \\
\hline Wooden Door & Wall & $\mathrm{Q}_{\text {flux }}=7.15 \mathrm{w} / \mathrm{m}^{2}$ \\
\hline C.P.U & Wall & $\mathrm{Q}_{\text {flux }}=110.8 \mathrm{w} / \mathrm{m}^{2}$ \\
\hline Human & Wall & $\mathrm{Q}_{\text {flux }}=77.64 \mathrm{w} / \mathrm{m}^{2}$ \\
\hline Monitor & Wall & $\mathrm{Q}_{\text {flux }}=180.9 \mathrm{w} / \mathrm{m}^{2}$ \\
\hline Light & Wall & $\mathrm{Q}_{\text {flux }}=22.22 \mathrm{w} / \mathrm{m}^{2}$ \\
\hline
\end{tabular}

VI. RESULTS

- Temperature contour after $120 \mathrm{~min}$

- At plane $9.6 \mathrm{~m}$ in $\mathrm{x}$ direction

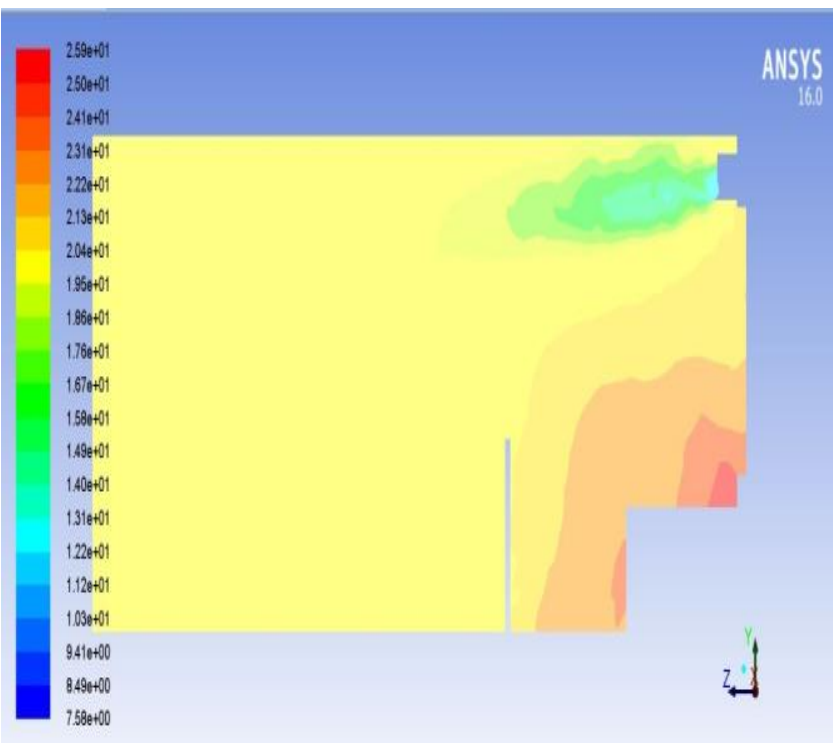

Fig 6. Temperature contour at plane $9.6 \mathrm{~m}$

Fig. 6, Fig. 7 and Fig. 8 are the temperature contour in different planes in $\mathrm{x}$ direction. From the temperature contour it can see that the temperature of in between spaces is around $21^{\circ} \mathrm{C}$ to $23^{\circ} \mathrm{C}$. It is see that temperature is higher near the north wall this is due to fact that this wall is directly exposed to outside. From Fig. 9 is can be seen that temperature around human is between 23 to $26^{\circ} \mathrm{C}$.Also near C.P.U higher temperature is observed .Also low temperature pockets can be seen which may cause local discomfort. 


\section{$\circ \quad$ At plane $5.6 \mathrm{~m}$ in $\mathrm{x}$ direction}

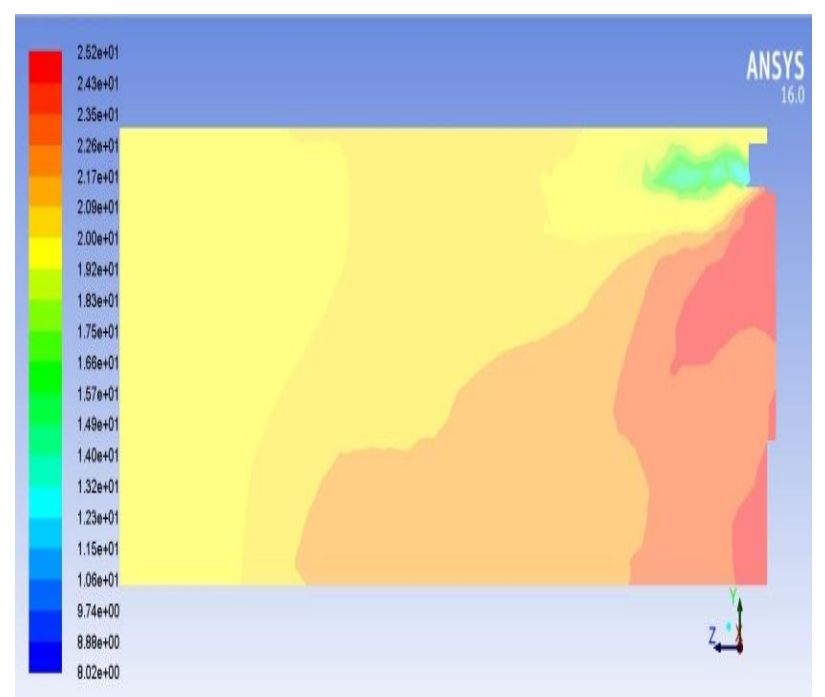

Fig 7. Temperature contour at plane $5.6 \mathrm{~m}$ $\circ \quad$ At plane $1.9 \mathrm{~m}$ in $\mathrm{x}$ direction

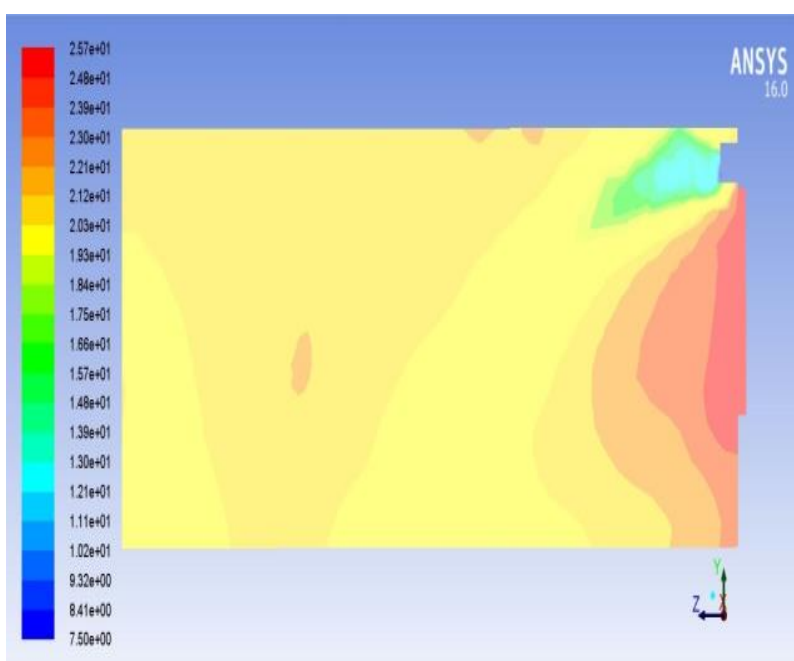

Fig 8. Temperature contour at plane $1.9 \mathrm{~m}$ - At plane $3.75 \mathrm{~m}$ in $\mathrm{z}$ direction

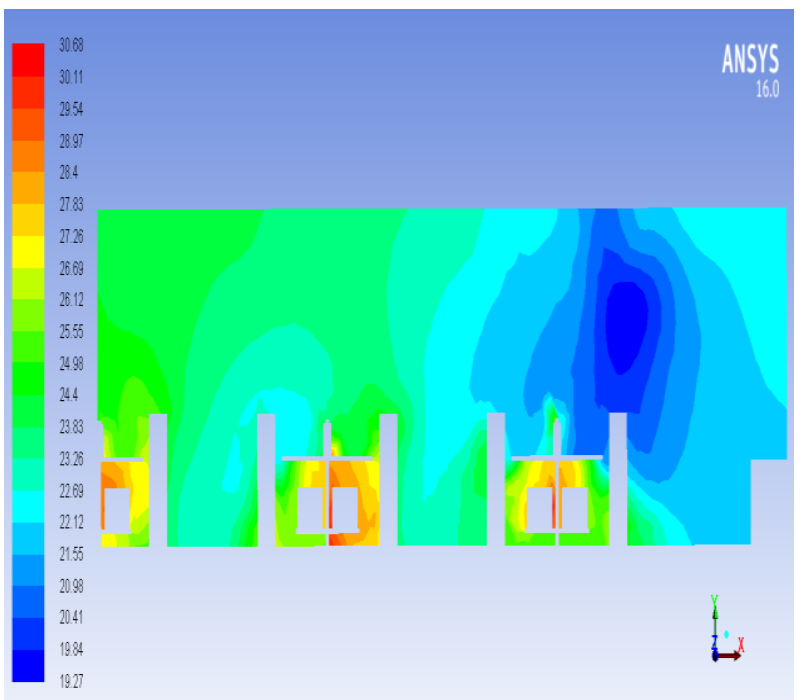

Fig 9. Temperature contour at plane $3.75 \mathrm{~m}$
- Velocity contour after $120 \mathrm{~min}$

$\circ \quad$ At plane $9.6 \mathrm{~m}$ in $\mathrm{x}$ direction

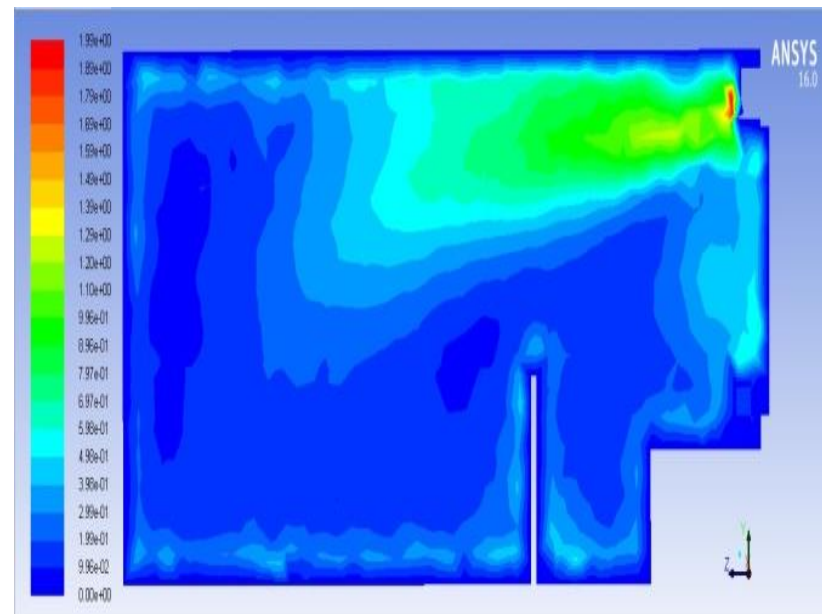

Fig 10 . Velocity contour at plane $9.6 \mathrm{~m}$

$\circ \quad$ At plane $5.6 \mathrm{~m}$ in $\mathrm{x}$ direction

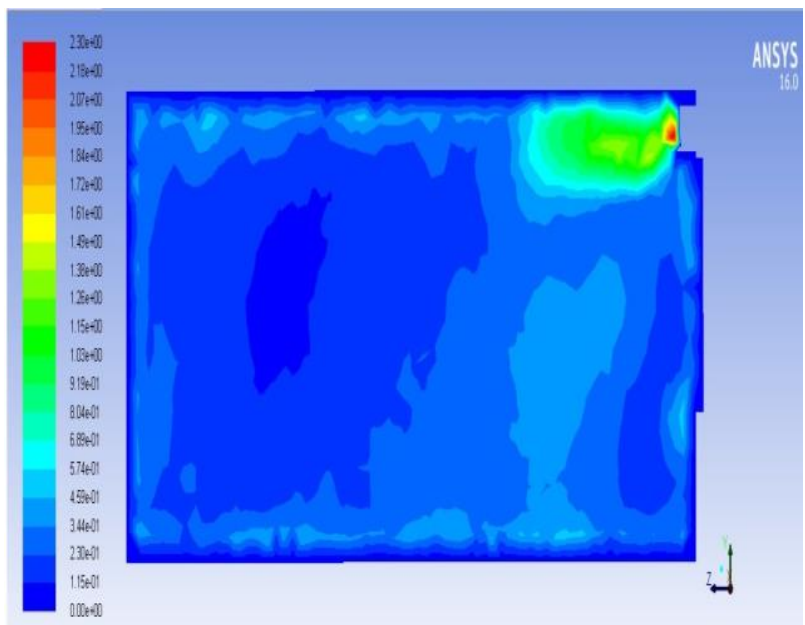

Fig 11 . Velocity contour at plane $5.6 \mathrm{~m}$ - At plane $1.9 \mathrm{~m}$ in $\mathrm{x}$ direction

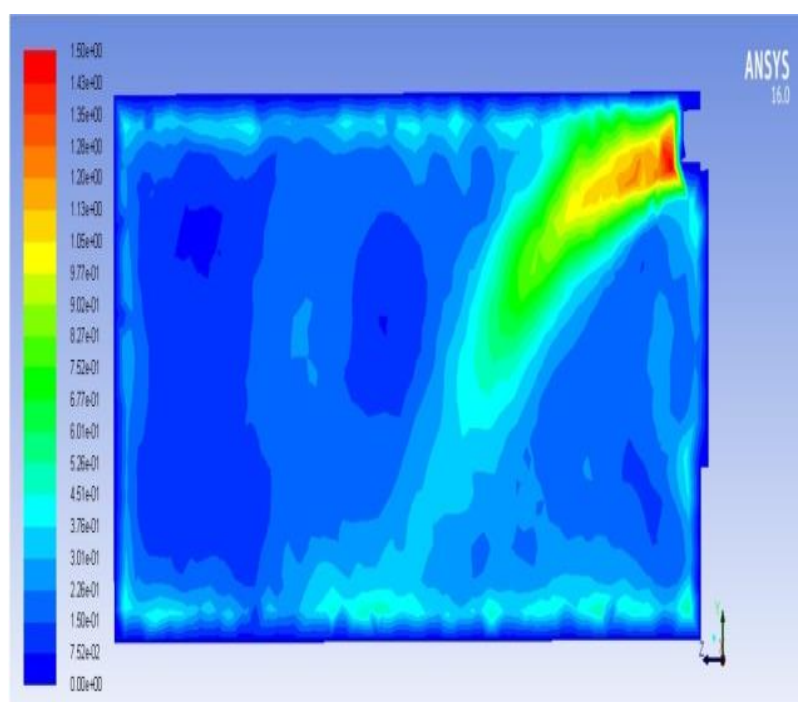

Fig 12 . Velocity contour at plane $1.9 \mathrm{~m}$ 
- At plane $3.75 \mathrm{~m}$ in $\mathrm{z}$ direction

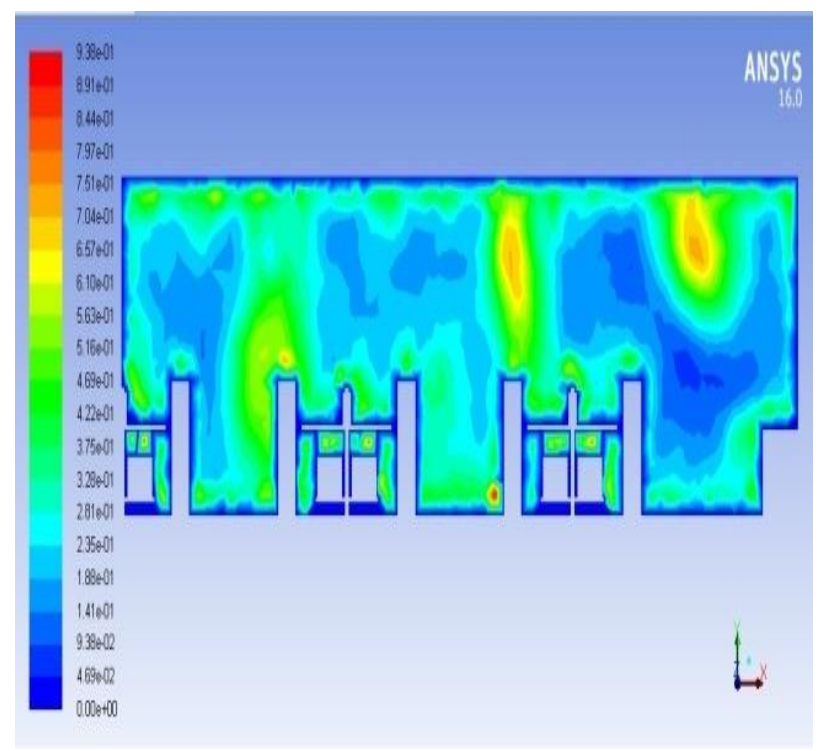

Fig 13 . Velocity contour at plane $3.75 \mathrm{~m}$

From Fig. 10, Fig. 11 and Fig. 12 it can be seen that for a large portion air is almost stagnant. Also in Fig. 9 low temperature pockets were there. Combination of both can cause discomfort at several location in the laboratory. Also from Fig.13 it can be seen that around head and foot air velocity is around 0.4 to $0.55 \mathrm{~m} / \mathrm{s}$ which may also cause discomfort.

\section{VALIDATION OF RESULTS}

Temperature behaviour at Point 6 with respect to time was numerically simulated and validated with the experimental results at same point which is shown in Fig. 14. Point 6 is considered for validation as it is in centre of the room.

From the Fig. 14 it can be seen that both the simulated and the experimental results have almost same trend and values are also close to each other. Therefore, we can say that the numerical model is validated with the experimental

The numerical results of thermal behaviour at other points in the room are shown in Fig. 15. The trends show similarity with the experimental results as shown in Fig. 3.

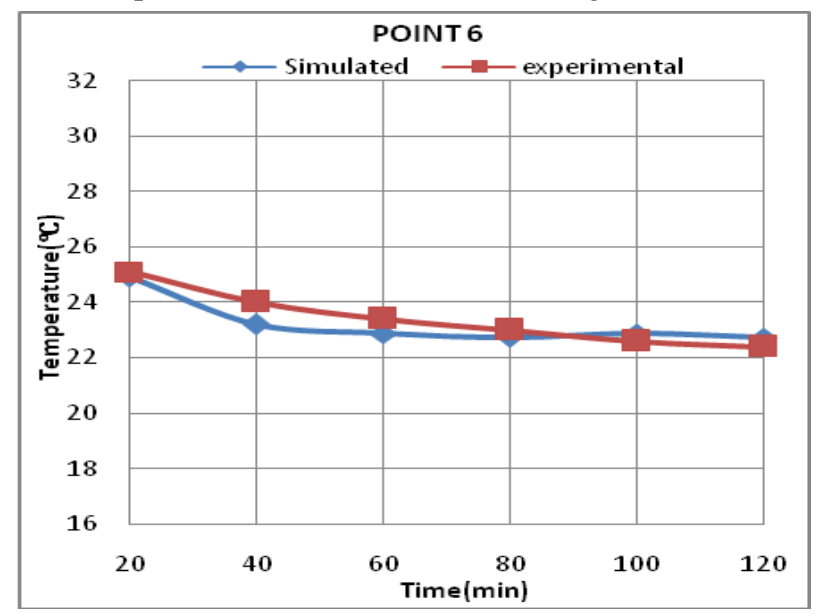

Fig 14. Temperature plot for point 6

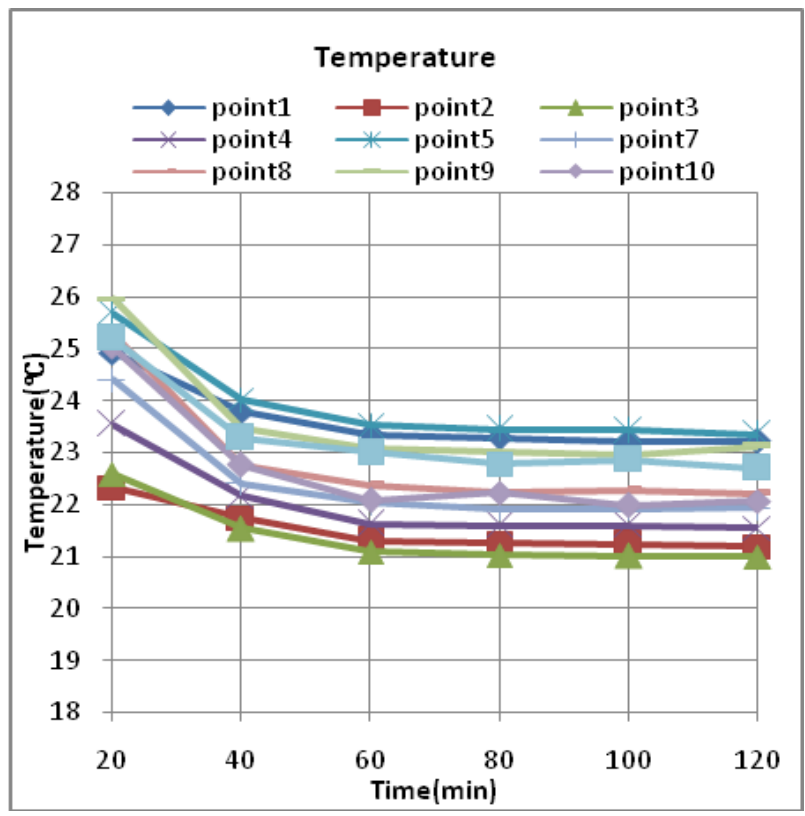

Fig 15. Temperature plot for different points

\section{CONCLUSION}

This study presents a comparison between the experimental data collected and the numerical data simulated. Numerical results are in close approximation with the experimental one. Computational fluid dynamic approach has predicted the air temperature and the flow pattern in the laboratory. The conclusions are as follows:

- Cooling load calculation shows grand total heat of 67863 $\mathrm{Btu} / \mathrm{hr}$ i.e. 5.7 ton of refrigeration is required for the laboratory. In this there is larger share of occupant load and appliance load .Occupants has major impact on the temperature distribution of the bottom half of the laboratory.

- Change in temperature for laboratory is about $5-6^{\circ} \mathrm{C}$ for experimental as well as simulated values. Also simulated values for temperature are bit lower than experimental values this is due to the fact that an airtight model is considered for simulation.

- Values for humidity ratio felled close to $40 \%$ which can cause a certain level of discomfort for occupants at certain temperatures.

- $\mathrm{CO}_{2}$ concentration has crossed limit of $1000 \mathrm{ppm}$ at the very beginning itself which is the limit set by ASHRAE. Also after end of 120 min soon it crossed 5000 ppm mark which is the hazardous limit.

- Temperature contour shows that there are some low temperature pockets and velocity contours show the area near human foot and head is high combined effect of which may cause local discomfort at that regions.

- Also by observing Velocity contour it can be seen that ample spots are there in laboratory which has close to zero velocity which shows that air is stagnant there so such zones have high $\mathrm{CO}_{2}$ concentration. So the air distribution should be design in order to reduce such zones. 


\section{REFERENCES}

[1] ASHRAE fundamentals handbook,2001

[2] ASHRAE Handbook - Fundamentals, 2005

[3] ASHRAE Handbook: Heating, Ventilating, and Air-conditioning Applications, 2007.

[4] ASHRAE standards 62.1-2013“"ventilation for acceptable IOQ"

[5] H. K. Versteeg and W. Malalasekera,2007, An Introduction to Computational Fluid Dynamics: The Finite Volume Method Longman Scientific and Technical.

[6] Li Yang, Miao Ye, Bao-Jie he, CFD simulation research on residentia indoor air quality, Science of the Total Environment 472,1137$1144,2014$.

[7] K Vaseemul Rahaman, Prof. Shankar Kumar,CFD Analysis of Ai Conditioning Equipment of CAD Lab for Enhancing its Performance, ISSN 2347 - 6435, Volume 4, Issue 11,2015.

[8] A.M. Wahhad, N. M. Adam and S.M. Sapuan.Comparison of numerical simulation and experimental study on indoor air quality of air-conditioned office building in desert climate,International Journal of Automotive and Mechanical Engineering,Volume 12, pg no.3109$3124,2015$.

[9] GuohuiGan,Evaluation of room air distribution systems using computational fluid dynamics,Energy and Buildings 23 ,pg no8393,1995

[10] Qingyan (Yan) Chen,Zhiqiang(John) Zhai, The use of cfd tools for indoor environmental design,Advanced Building Simulation, pg. 119140,2004

[11] M Raman ME,Computational fluid dynamics analysis of HVAC system in auditorium,International Journal of Advanced Research and Development, Volume 1, Issue 5, Page No. 68-72; May 2016.

[12] Mao Ning, Song Mengjie. Chan Mingyin, Pan Dongmie, Deng Shiming. Computational fluid dynamics (CFD) modeling of air flow field, mean age of air and $\mathrm{CO}_{2}$ distributions inside a bedroom with different heights of conditioned air supply outlet ,Applied Energy, 164:906-15,2016

[13] M. Hussin , M.R. Ismail , M.S. Ahmad, Air-conditioned university laboratories: Comparing $\mathrm{CO}_{2}$ measurement for centralized and splitunit systems, Journal of King Saud University - Engineering Sciences, Volume 29, Issue 2,Pages 191-201,2017.

[14] MerveKuru,GulbenCalis, Investigating the Link between $\mathrm{CO}_{2}$ Concentration, Thermal Comfort and Occupant Perception in Educational Buildings, Proceedings of the Symposium on Simulation for Architecture and Urban Design,2018.

[15] Qinghe Yao ,Hang Bai,TrevorHocksun Kwan, and KiwamuKase, A Parametric Study and Optimization of an Air Conditioning System for a Heat-Loaded Room, Mathematical Problems in Engineering Volume,Article ID 2385691,2018.

[16] S.M.ShivaNagendra,M.P.Maiya,M.Jotirmay,K.Uma,A.Yogesh,M.Mam atha,YaparlaDeephti,Lakshmi Menon,ShailendraKumar,Methodology for IEQ standard implementation in different types of buildings, Air conditioning and refrigeration journal of ISHRAE,volume12 Number 5,pg no38-60,October2018 